\title{
PERANCANGAN SISTEM PENGGERAK TRAINER TRANSMISI MANUAL 5 PERCEPATAN
} TOYOTA KIJANG

\author{
Mohammad Munib Rosadi \\ Prodi Teknik Mesin Fakultas Teknik Universitas Hasyim Asy'ari \\ Email: munib.rosadi@gmail.com \\ Retno Eka Pramitasari \\ Prodi Teknik Mesin Fakultas Teknik Universitas Hasyim Asy'ari \\ Email: retnomita91@gmail.com \\ Ali Hasbi Ramadani \\ Prodi Teknik Mesin Fakultas Teknik Universitas Hasyim Asy'ari \\ Email: alihasbi89@yahoo.com
}

\begin{abstract}
Abstrak
Kebutuhan akan media belajar pada mata kuliah Elemen Mesin II menjadikan trainer transmisi untuk segera dihadirkan guna menjadi sarana pendukung pembelajaran mahasiswa. Di dalam sebuah sistem trainer transmisi diperlukan mekanisme penggerak agar transmisi dapat berputar. Mekanisme penggerak harus dapat diandalkan guna menjamin transmisi dapat berputar tanpa kendala. Maka dari itu perlu dilakukan desain dan perhitungan dalam merancang mekanisme penggerak transmisi. Tujuan dari penelitian ini adalah mengetahui desain dan perhitungan sistem penggerak trainer transmisi. Hasil perancangan menunjukkan bahwa spek motor yang diperlukan adalah motor dengan daya 250 watt, driver pulley diameter $50 \mathrm{~mm}$, driven pulley diameter $250 \mathrm{~mm}$, jarak antar sumbu pulley adalah $335 \mathrm{~mm}$. menggunakan $v$-belt tipe A dengan panjang $1175 \mathrm{~mm}$. mekanisme sistem penggerak ini akan menghasilkan torsi akhir sebesar 393,01 kg.mm yang mana dinilai baik karena lebih tinggi dari torsi rencana yaitu $325,85 \mathrm{~kg} . \mathrm{mm}$.
\end{abstract}

Kata Kunci: transmisi manual, trainer, pulley, v-belt.

\begin{abstract}
The need for learning media in the Machine Element II course makes the transmission trainer to be immediately presented in order to become a means of supporting student learning. In a transmission trainer system a driving mechanism is needed so that the transmission can rotate. The drive mechanism must be reliable to ensure the transmission can rotate without constraints. Therefore, it is necessary to design and calculate in designing the transmission driving mechanism. The purpose of this study was to determine the design and calculation of the transmission trainer drive system. The design results show that the required motor specs are motors with 250 watts of power, driven pulley diameter $50 \mathrm{~mm}$, driven pulley diameter $250 \mathrm{~mm}$, distance between pulley axes is $335 \mathrm{~mm}$. use v-belt type A with a length of 1175 $\mathrm{mm}$. this drive system mechanism will produce a final torque of $393.01 \mathrm{~kg} . \mathrm{mm}$ which is considered good because it is higher than the planned torque that is $325,85 \mathrm{~kg} . \mathrm{mm}$.
\end{abstract}

Keywords: manual transmission, trainer, pulley, v-belt 


\section{PENDAHULUAN}

Sistem transmisi dalam dunia otomotif merupakan sistem yang berfungsi untuk mengkonversi torsi dan putaran dari mesin menjadi torsi dan kecepatan yang berbeda-beda untuk diteruskan ke roda[1]. Transmisi memasok beberapa rasio gigi dari poros input menuju poros output untuk profil kecepatan dan torsi yang sesuai dengan bebannya [2]. SIstem transmisi mencakup tiga subsistem yaitu poros input output, gigi kecepatan dan syncronyzer[3]. Dalam pengoperasiannya sistem transmisi memiliki dua jenis mekanisme yaitu transmisi manual dan transmisi otomatis. Pada transmisi manual, perpindahan gigi dilakukan menggunakan pedal dan tuas kopling. Ketika ingin memindah gigi, maka pedal kopling diinjak terlebih dahulu untuk menciptakan putaran bebas pada gearbox kemudian dilepas pelan-pelan[4]. Pada transmisi otomatis tidak dilengkapi dengan pedal kopling sehingga pada proses perpindahan gigi hanya perlu memindah tuas mode transmisi saja.

Dalam mekanisme transmisi terdapat mekanisme roda gigi yang bekerja bergantian untuk memberikan rasio kecepatan dan torsi sesuai dengan yang diinginkan pengendara. Mekanisme roda gigi ini merupakan bagian dari konstruksi sistem transmisi yang memiliki tugas tertentu yang selanjutnya disebut dengan elemen mesin.

Dalam dunia akademis, elemen-elemen pada suatu konstruksi mesin juga dipelajari pada jenjang perguruan tinggi dalam bentuk matakuliah elemen mesin. Matakuliah ini merupakan matakuliah yang membahas elemen-elemen yang membentuk sebuah sistem yaitu mesin, termasuk di dalamnya mekanisme daya dan pemindah daya. Dalam prosesnya,pembelajaran pada mata kuliah ini memerlukan media dalam penyampaiannya. Mata kuliah ini merupakan matakuliah terapan yang memerlukan contoh langsung dari prinsipprinsip dan teori yang telah dipelajari.

Kondisi Universitas Hasyim Asy'ari yang masih dalam tahap berkembang belum memiliki media belajar yang lengkap terutama pada jurusan Teknik mesin. Dalam hal ini pembelajaran mata kuliah elemen mesin memerlukan media belajar yang dapat membantu mahasiswa meneruskan teori yang telah dipelajari ke dalam benda nyata.

Menimbang hal di atas, peneliti berkeinginan untuk membuat trainer transmisi yang dapat dimanfaatkan dalam pembelajaran mata kuliah elemen mesin khususnya pada materi belt, pulley dan roda gigi. Namun hal yang terpenting dari trainer ini adalah sistem penggeraknya. Sistem penggerak berfungsi untuk menggerakkan trainer agar mampu beroperasi sehingga membutuhkan perencanaan yang matang sehingga diharapkan trainer akan dapat beroperasi sesuai dengan apa yang diinginkan. Perumusan masalah meliputi desain sistem dan perhitungannya. Tujuan penelitian untuk menghasilkan desain penggerak trainer yang sesuai dengan kriteria minimal yaitu mendesain dan merancang sistem penggerak yang mampu menggerakkan trainer transmisi manual sebagai media pembelajaran.

\section{METODE \\ Rancangan Penelitian}

Gambar 1 dibawah ini menunjukkan diagram alir perancangan sistem penggerak trainer transmisi manual.

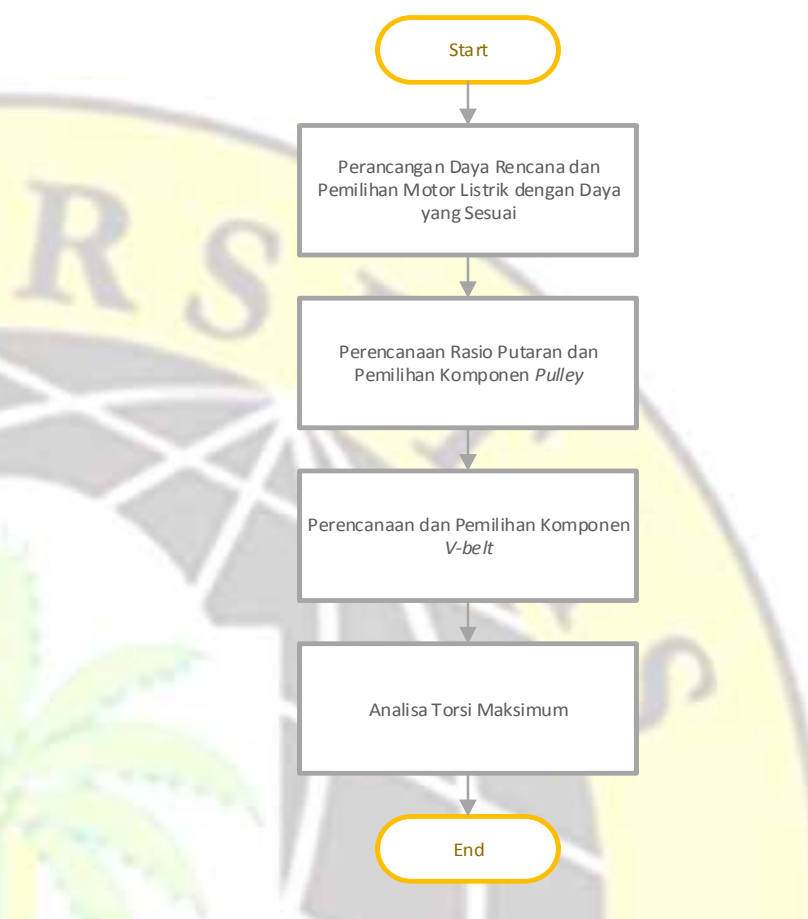

Gambar 1. Rancangan Penelitian

\section{Desain Alat}

Gambar 2 dibawah ini menunjukkan rancangan desain sistem penggerak trainer transmisi manual.



Gambar 2. Desain Sistem Penggerak Trainer

$\begin{array}{ll}\text { Spesifikasi Motor } & \\ \text { Merk } & : \text { Yuasa } \\ \text { Tipe } & : \text { Motor Cluth } \\ \text { Putaran } & : 2850 \mathrm{rpm} \\ \text { Daya } & : 250 \mathrm{watt}\end{array}$




\section{Prosedur Penelitian}

Pertama-tama peneliti melakukan perhitungan daya rencana yang dibutuhkan untuk menggerakkan transmisi yang mana akan disesuaikan dengan pemilihan motor yang ada di pasaran. Selanjutnya melakukan perencanaan rasio putaran yang diinginkan. Kemudian perhiungan driver dan driven pulley beserta $v$-belt yang mana juga disesuaikan dengan ketersediaan komponen tersebut di pasaran. Terakhir malakukan analisa menyeluruh terhadap komponen yang diasumsikan dirangkai mnejadi driving system.

\section{Teknik Analisis Data}

Analisis data menggunakan deskriptif kuantitatif. Tujuan dari metode deskriptif kuantitatif adalah untuk membaur deskripsi, gambaran atau lukisan secara sistematis, factual dan akurat mengenai fakta-fakta, sidfat-sifat, atau hubungan antar fenomena yang diselidiki[5]. Data yang dikumpulkan kemudian dideskripsikan.dalam bentuk kalimat yang mudah dibaca dan dimengerti.

\section{HASIL DAN PEMBAHASAN}

Torsi Transmisi

Torsi pada transmisi dapat diketahui dengan menggunakan rumus[6] berikut ini:

$$
T=F \times l
$$

$$
T=3,430 \mathrm{~kg} \times 95 \mathrm{~mm}=325,85 \mathrm{~kg} \cdot \mathrm{mm}
$$

Dimana:

$$
\begin{array}{ll}
T & : \text { Torsi } \\
F & : \text { Gaya yang dibutuhkan } \\
l & \text { : Panjang lengan }
\end{array}
$$

Untuk menentukan daya rencana $\left(P_{d}\right)$ pada trainer transmisi manual perlu didesain rasio kecepatan. Rasio kecepatan trainer ditentukan 1 : 5 yang mana didasarkan pada rasio diameter pulley. Driven pulley ditentukan 250 $\mathrm{mm}$ karena sudah dalam ambang batas ukuran. Driven pulley masuk ke dalam rumah kopling yang mana besarnya driven pulley harus lebih kecil daripada rumah kopling. Sehingga didapat pula nilai diameter driver pulley sebesar $50 \mathrm{~mm}$. Motor yang akan digunakan dipilih dari jenis motor mesin jahit konveksi yang memiliki mekanisme kopling. Hal ini berfungsi ketika pada saat pengoperasian trainer akan melakukan perpindahan gigi tidak harus mematikan motor namun tinggal menarik tuas koplingnya saja. Motor mesin jahit konveksi yang tersedia di pasaran saat ini adalah 250 watt = 0,335 HP. berputar maksimal $2850 \mathrm{rpm}$, berarti putaran rencananya adalah $2850 / 5=570 \mathrm{rpm}$. Sehingga daya rencananya dapat dicari dengan rumus [6] sebagai berikut:

$$
P_{d}=\frac{\left(\frac{T}{1000}\right)\left(\frac{2 \pi n_{1}}{60}\right)}{102}
$$

$$
\begin{aligned}
& P_{d=} \frac{\left(\frac{325,85}{1000}\right)\left(\frac{2 \times 3,14 \times 690}{60}\right)}{102}=\frac{(0,32585)(72,22)}{102} \\
& P_{d}=0,230 \mathrm{~kW}=0,308 \mathrm{HP}
\end{aligned}
$$

Dimana:

$P_{d}:$ Daya rencana

$T$ : Torsi rencana

$\pi$ : Konstanta

$n_{1}:$ Putaran rencana

Adapun daya motor yang dipilih harus lebih besar dari daya rencana. Dengan demikian daya motor yang dipilih sesuai pasaran adalah sebesar 250 watt $=0,33 \mathrm{HP}$.

\section{Perancangan Transmisi Daya}

Perencanaan transmisi daya pada trainer ini menggunakan driver pulley, v-belt dan driven pulley seperti tertera pada Gambar 2 pada bagian sebelumnya. Rasio putarannya dapat dilihat pada Gambar. 3 dibawah ini:

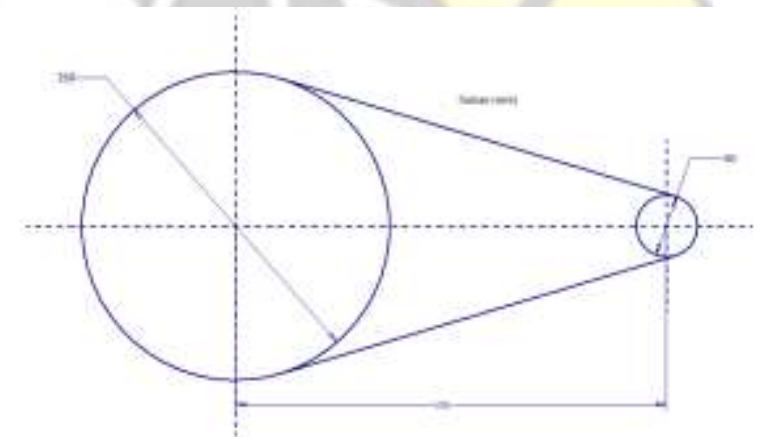

Gambar 3. Dimensi driver pulley, belt dan driven pulley

Rasio putaran yang digunakan adalah 1:5 dengan putaran motor $2850 \mathrm{rpm}$. Diameter lingkaran jarak bagi driver pulley dan driven pulley berturut-turut adalah $d_{p}$ dan $D_{p}$.

$D_{p}=250 \mathrm{~mm}$

$$
d_{p}=50 \mathrm{~mm}
$$

Diameter luar puli penggerak dan puli yang digerakan berturut-turut adalah $d_{k}$ da $D_{k}$.

$$
\begin{aligned}
& d_{k}=50+2 \times 5,5=61 \mathrm{~mm} \\
& D_{k}=250+2 \times 5,5=261 \mathrm{~mm}
\end{aligned}
$$

Adapun jarak sumbu poros dengan kedua puli (C) yang dipilih adalah $335 \mathrm{~mm}$ dengan syarat rumus[6] dibawah.

$$
\begin{aligned}
& C>\frac{d_{k}+D_{k}}{2} \\
& C>\frac{61+261}{2} \\
& C>161 \mathrm{~mm}
\end{aligned}
$$


Dari (C) yang sudah diketahui maka selanjutnya adalah menentukan panjang sabuk (L), berikut adalah rumus[6] perhitungan untuk panjang sabuk.

$$
\begin{aligned}
\mathrm{L} & =2 \mathrm{C}+\frac{\pi}{2}\left(d_{p}+D_{p}\right)+\frac{1}{4 C}\left(D_{p}-d_{p}\right)^{2} \\
\mathrm{~L} & =2(335)+\frac{\pi}{2}(50+250)+\frac{1}{4(335)}(250-50)^{2} \\
\mathrm{~L} & =670+1,57(300)+\frac{1}{1340} 40000 \\
\mathrm{~L} & =670+471+29,8 \\
\mathrm{~L} & =1170,8 \mathrm{~mm}
\end{aligned}
$$

Pemilihan panjang sabuk sesuai pasaran adalah $12,5 \mathrm{x}$ 1175 La seperti terlihat pada gambar di bawah ini:

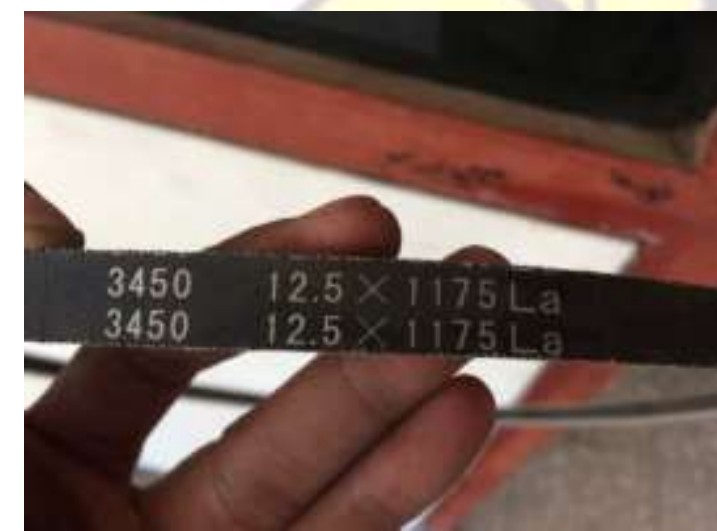

Gambar 4. V-belt $12.5 \times 1175 \mathrm{La}$

\section{Analisa Torsi Maksimum terhadap Torsi Rencana}

Torsi makimum diberikan pada bagian driven pulley transmisi $v$-belt sisi B dengan menggunakan rumus persamaan 5 dan 6 .

$$
\begin{aligned}
& \text { T output } \\
& >T
\end{aligned}
$$

\section{Dimana:}

$T_{\text {output }}$ : Torsi output transmisi

$T \quad$ : Torsi rencana $(325,85 \mathrm{~kg} . \mathrm{mm})$

Adapun untuk rumus[6] torsi output sendiri adalah:

$$
\begin{aligned}
& \text { T output } \\
& =9,74 \times 10^{5} \frac{P_{d}}{n_{1}}
\end{aligned}
$$

$$
\begin{aligned}
& \text { Toutput }=393,01 \mathrm{~kg} \cdot \mathrm{mm} \\
& \begin{array}{r}
(T \text { output }=393,01 \mathrm{~kg} . \mathrm{mm})>(T \\
=325,85 \mathrm{~kg} . \mathrm{mm})
\end{array}
\end{aligned}
$$

Kesimpulan analisa torsi pada driven pulley adalah baik karena $\mathrm{T}_{\text {output }}$ lebih besar dari $\mathrm{T}$.

\section{PENUTUP \\ Simpulan}

1. Dibutuhkan torsi (T) minimal sebesar $325,85 \mathrm{~kg} . \mathrm{mm}$ untuk memutar poros transmisi.

2. Dibutuhkan daya rencana $\left(P_{d}\right)$ sebesar $0,308 \mathrm{HP}$ untuk menggerakkan poros transmisi.

3. Untuk memenuhi daya rencana sebesar 0,308 HP maka daya mesin penggerak (motor listrik) yang dipilih adalah 250 Watt $=0,335 \mathrm{HP}$ sesuai dengan yang tersedia di pasaran.

4. Transmisi daya dari pulley motor (driver pulley) ke gearbox (driven pulley) adalah v-belt, dengan rasio putaran 1:5, tipe sabuk A 12,5 x $1175 \mathrm{La}$, diameter driver pulley adalah $50 \mathrm{~mm}$ dan driven pulley 250 $\mathrm{mm}$, jumlah sabuk yang digunakan adalah satu, dan jarak sumbu poros sebesar $335 \mathrm{~mm}$.

5. $\mathrm{T}_{\text {output }}$ yang dicapai pada driven pulley adalah 393,01 kg.mm dinilai baik karena lebih tinggi dari $\mathrm{T}$ yaitu 325,85 kg.mm

\section{Saran}

1. Trainer ini dapat digunakan untuk mahasiswa sebagai sarana belajar mata kulah Elemen Mesin II khususnya materi belt, pulley dan roda gigi.

2. Pada penelitian selanjutnya hendaknya dilakukan perhitungan torsi minimum untuk masing-masing persneling.

\section{DAFTAR PUSTAKA}

[1] Wikipedia. 2019. Sistem Transmisi. [Online]. https://id.wikipedia.org/wiki/Sistem transmisi.

[2] P. Bera, "A design method of selecting gear ratios in manual transmissions of modern passenger cars," Mechanism and Machine Theory 132 (2019) 133-153.

[3] Wikipedia. 2019. Manual Transmission. [Online]. https://en.wikipedia.org/wiki/Manual transmission.

[4] M.Y. Wang, R. Manoj, and W. Zhao, "Gear rattle modelling and analysis for automotive manual transmissions," Proceedings of the Institution of Mechanical Engineers, Part D: Journal of Automobile Engineering, 2001, pp 215-241.

[5] Nazir, Moh. 2005. Metode Penelitian. Jakarta: Ghalia Indonesia

[6] Sularso, K. Suga. 1985. Dasar Perencanaan dan Pemilihan Elemen Mesin. Jakarta: Pradnya Paramita.

\section{$P_{d}:$ Daya Motor $(\mathrm{kW})$}

$n_{1}$ : Putaran yang dihasilkan (rpm)

Perbandingan putran input dengan output dari transmisi v-belt adalah $1: 5$, maka output putaran dari driver pulley ke driven pulley adalah $570 \mathrm{rpm}$.

$$
\text { T output }=9,74 \times 10^{5} \frac{0,230}{570}
$$

